\title{
Diencephalic epilepsy in a patient with agenesis of the corpus callosum confirmed by computerised axial tomography
}

\author{
D A VID CARR-L OCKE A N P A U L M I L A C \\ From the Royal Infirmary, Leicester
}

SUMMARY A case of diencephalic epilepsy is described in whom stereotyped attacks of spontaneous hypothermia and diaphoresis occurred over a 20 year period. No abnormality of the hypothalamo-pituitary-adrenal axis was found, and there was no evidence of an intracranial mass lesion. Pneumoencephalography and computerised axial tomography (EMI scan) demonstrated agenesis of the corpus callosum.

Spontaneous hypothermia is rare in the adult when it is not associated with low environmental temperature, myxoedema, or drug intoxication. A syndrome of spontaneous periodic hypothermia was first recognised by Gowers (1907) when patients with 'vasovagal' attacks were noticed to sweat profusely and become very cold. He prorosed that these were seizures from diencephalic centres. Penfield (1929) coined the term diencephalic epilepsy for a woman with such attacks subsequently found to have a tumour in the dorsal medial nucleus of the thalamus. Since then there have been several reports of spontaneous hypothermia associated with diencephalic neoplasms (Ratner, 1925; Obregia et al., 1932; McLean, 1934; Davison and Selby, 1935; Davison and Demuth, 1946; Sunderman and Haymaker, 1947; Kaplan et al., 1952; Bauer, 1954; Wechsler, 1956; Solomon, 1973), and other focal hypothalamic disease (Hockaday et al., 1962; Bannister, 1963; Fox et al., 1970), but these were usually preterminal events, rarely episodic and sometimes followed surgery.

Hines and Bannick (1934) described a more stereotyped syndrome, later supported by other case reports (Hoffman and Pobirs, 1942; Duff et al., 1961; Shapiro et al., 1969; Siniavskaia, 1970; Guihard et al., 1971; Fox et al., 1973; Nöel et al., 1973; Thomas and Green, 1973a; Dutau et al., 1975), consisting of spontaneous falls in core body

Address for correspondence and reprint requests: Dr D. L. Carr-Locke, Department of Medicine, General Hospital, Gwendolen Road, Leicester LE5 4PW, England.

Accepted 4 March 1977 temperature to levels of $35^{\circ} \mathrm{C}$ or less, associated with paroxysms of coordinated thermoregulatory and vasomotor activity. These were characterised by bradycardia, hypotension, cerebral impairment, and intensive inappropriate cutaneous vasodilatation with sweating. Shapiro et al. (1969) first described agenesis of the corpus callosum in two patients with diencephalic epilepsy. Of the 12 cases reported in the literature, five had agenesis of the corpus callosum (Shapiro et al., 1969; Guihard et al., 1971; Noël et al., 1973; Dutau et al., 1975), three had normal pneumoencephalography (Duff et al., 1961; Fox et al., 1973; Thomas and Green, 1973a), and four were not fully investigated (Hines and Bannick, 1934; Hoffman and Pobirs, 1942; Duff et al., 1961; Siniavskaia, 1970).

We report here a further example of this apparently rare condition in whom an EMI scan was found to be helpful in confirming the presence of agenesis of the corpus callosum.

\section{Case report}

A 28 year old housewife was admitted to Leicester General Hospital in April 1974, when noticed to be unwell while attending a paediatric clinic with her three month old son. She complained of sweating and feeling cold. Her thought and comprehension were slow and she made little spontaneous speech or movement, making it difficult to obtain further information at that stage. She appeared flushed, and generalised sweating drenched her clothing. Initial oral temperature was $32^{\circ} \mathrm{C}$. Other findings were a regular pulse of 40 beats $/ \mathrm{min}$, a 
blood pressure of $90 / 60 \mathrm{mmHg}$, a fixed expression, a flapping tremor, an ataxic gait with falling to the left, mild cerebellar signs in the arms, ataxic nystagmus on left lateral gaze, and equivocal flantar responses. Two hours later her symptoms had resolved, her oral temperature was $35^{\circ} \mathrm{C}$, pulse $72 / \mathrm{min}$, and blood pressure $130 / 90 \mathrm{mmHg}$.

Subsequently it emerged that from the age of 8 years she had had intermittent attacks of profuse sweating and feeling cold for several months at a time with free intervals of between six months and nine years. She was considered to behave abnormally during attacks, being withdrawn and uncommunicative. When aged 17 years her attacks returned, and six years later she presented again with weight loss for three months, severe drenching sweats with nausea, cold flushed skin and withdrawn behaviour, remitting spontaneously two months later. When aged 24 years she completed a full term normal pregnancy followed by further sweating attacks. In the year before admission, during her second pregnancy oral glucose tolerance tests were of diabetic type at 30 and 32 weeks gestation and an uneventful labour followed induction at 38 weeks. Her attacks had returned at the 28th week of pregnancy, and at five and eight hours post-partum she complained of severe sweating when oral temperatures were recorded as $35^{\circ} \mathrm{C}$ although a standard clinical thermometer had been used for all recordings. Attacks became more frequent two months postpartum, being almost daily. In addition to her usual symptoms she described episodic amnesia and feelings of being distant. Episodes were now lasting from 30 minutes to three hours and were occasionally terminated by shivering. They usually occurred in the mornings at about 0600 when she would drench the bedclothes. Between attacks she appeared normal in every respect. There was no family history.

While in hospital the stereotyped pattern of her attacks was confirmed, and a record of her temperature, pulse and blood pressure is shown in Fig. 1. Typically she would wake at 0500 to 0600 , when her oral temperature was $35^{\circ}$ to $36^{\circ} \mathrm{C}$, and begin to sweat profusely such that her temperature fell over two to three hours to between $30^{\circ}$ and $32^{\circ} \mathrm{C}$. There was always a bradycardia, hypotension, peripheral vasodilatation, and a change in mental state. At the end of an attack rectal and

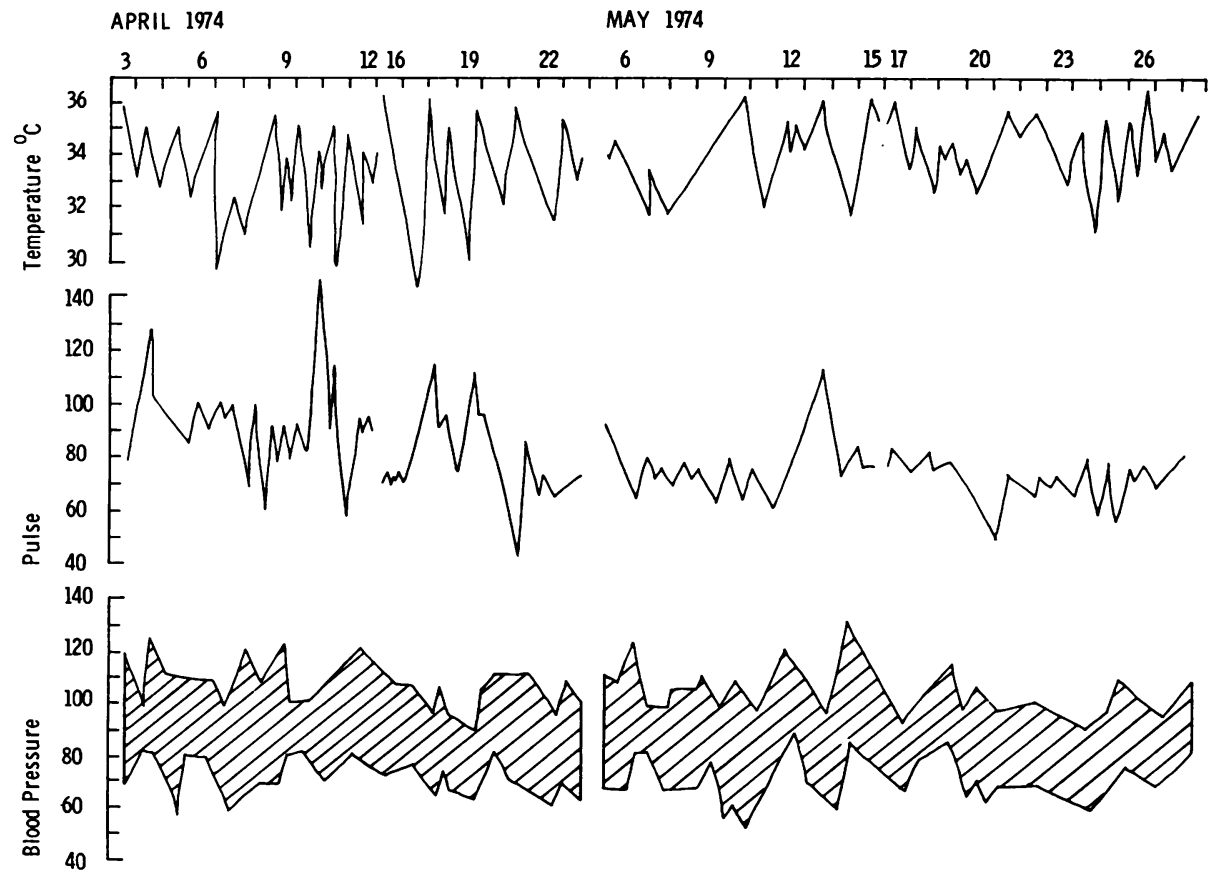

Fig. 1 Records of oral temperature, pulse (beats/min), and blood pressure ( $\mathrm{mmHg}$ ) during a discontinuous two month period in hospital demonstrating the abrupt falls in temperature accompanied by bradycardia and hypotension. Anticonvulsant therapy and thermal studies in late A pril and May had no effect on the pattern of attacks. 
oral temperatures would rise to basal levels, with or without shivering, although this progression could be interrupted at any time by a further attack.

There was no obvious effect on the onset, duration, or severity of attacks by changing her environmental temperature. Results of other thermal studies demonstrated that between attacks heat dissipating mechanisms seemed to operate normally on external warming but were invoked at temperatures lower than expected such that she maintained a core temperature of about $35.5^{\circ} \mathrm{C}$. Cooling produced a response in heat conserving mechanisms but she could tolerate falls in oral temperature down to $31^{\circ} \mathrm{C}$ before shivering occurred.

Laboratory investigations showed normal renal, thyroid and liver function tests, haematology, and serum and urinary calcium and phosphate levels. Blood glucose levels during attacks ranged from 3.85 to $7.9 \mathrm{mmol} / 1$ (69 to $142 \mathrm{mg} / \mathrm{dl}$ ). A five hour oral glucose tolerance test was normal and growth hormone showed normal suppression. Twenty four hour urinary 17-oxogenic steroids, oxosteroids, luteinising hormone and follicle stimulating hormone levels were normal. Insulin stimulation using 0.2 units $/ \mathrm{kg}$ produced normal elevations of growth hormone and cortisol. There was a normal response to water deprivation. Serology (including Brucella), urinary vanillylmandelic acid and 5-hydroxyindole acetic acid, electrocardiograph, visual field charting, examination of cerebrospinal fluid, chest and skull radiographs, and isotopic brain scan were all normal.

Two electroencephalograms showed a diffusely abnormal record with theta activity replacing alpha and frequent bursts of high voltage delta waves bilaterally but not synchronously. These increased with hyperventilation but not with photic stimulation and were considered to be consistent with a deep midline lesion.

Psychometric assessment showed full scale IQ of 118 (Weschsler Adult Intelligence Scale) and a normal personality profile.

Bilateral carotid angiography showed a normal sweep of pericallosal vessels with no separation to indicate that the genu of the corpus callosum was present. The inferior sagittal sinus was not visualised. The straight sinus was low in position. Internal cerebral veins were normal in position and were not separated but there was absence of the normal $U$ of the vein of Galen.

Pneumoencephalography showed wide displacement of the lateral ventricles with depression of the tentorium cerebelli and aqueduct. The third ventricle was normal in size but elevated in position. Although the appearances were consistent with agenesis of the corpus callosum, a midline cyst or tumour of the septum pellucidum could not be excluded (Figs. 2 and 3 ).

EMI scan (Fig. 4) confirmed wide separation of the lateral ventricles but the tissue density between them was normal. This did not alter after intravenous injection of contrast medium (meglumine iothalamate, Conray 280 ). The third ventricle was elevated but not enlarged and the conclusion was that she had partial agenesis of the corpus callosum.

A trial of barbiturate and phenytoin produced no effect on her attacks and these continued almost daily, becoming less severe, until June 1975 when they stopped spontaneously. She has remained well since then without treatment.

\section{Discussion}

From 39 case reports of spontaneous hypothermia, 12 stand out as conforming to a particular pattern accepted here as diencephalic epilepsy. Shapiro et al. (1969) have summarised the case for accepting this syndrome as a species of epilepsy but this classification has by no means been widely accepted (Leader, 1973). Thomas and Green (1973b) find it difficult to accept some cases as epileptic (Duff et al., 1961; Thomas and Green, 1973a) because of the long episodes of hypothermia. All 12 cases with ours, however, have had short attacks of no more than a few hours duration of which only three were superimposed on more prolonged periods of hypothermia of up to four weeks (Duff et al., 1961; Shapiro et al., 1969; Thomas and Green, 1973a). Indeed two cases had overt grand mal epilepsy in addition (Duff et al., 1961; Thomas and Green, 1973a).

The disappointing feature of diencephalic epilepsy is its poor response to conventional anticonvulsants with only two cases responding to barbiturates (Hines and Bannick, 1934; Hoffman and Pobirs, 1942). The two cases of grand mal epilepsy were controlled on phenobarbitone and phenytoin but their hypothermic attacks were unaffected. One patient, after unsuccessful drug trial including topical poldine (Cunliffe et al., 1971) was eventually relieved of her disabling symptoms by total sympathectomy (Fox et al., 1973). The remaining nine cases seemed to undergo a relapsing and remitting course. Our patient similarly showed no response to normal therapeutic doses of anticonvulsants but remitted spontaneously 20 months after the onset of symptoms. 
The more severe forms of agenesis of the corpus callosum are marked by mental and physical retardation with convulsions. Experimental and surgical section of the corpus callosum have not produced defects in temperature control (Sperry, 1961; Geschwind, 1965), and it is presumably not agenesis of the corpus callosum per se which is responsible for the diencephalic epilepsy but the associated defects (Bossy, 1970). Noël et al. (1973)

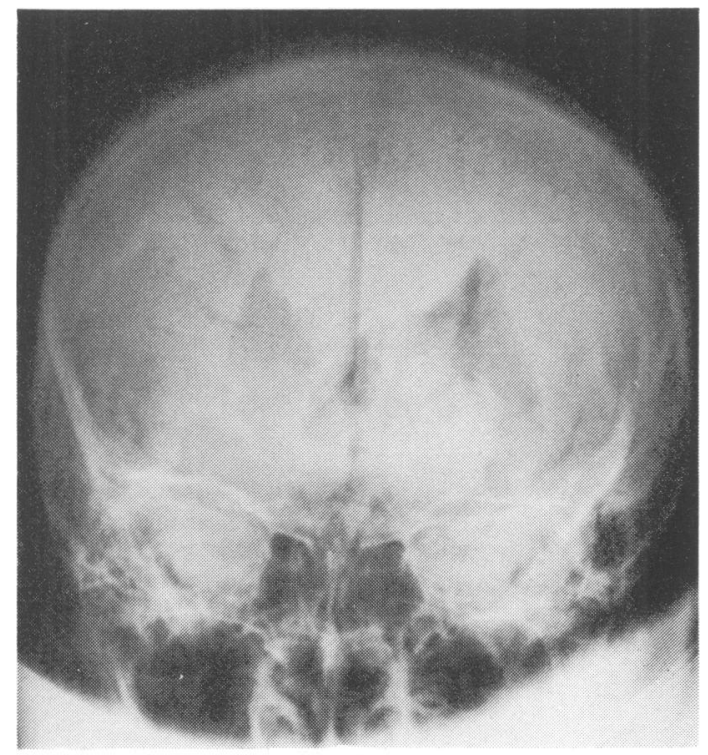

Fig. 2 in their postmortem study of a patient with diencephalic epilepsy add greatly to our knowledge of these structural abnormalities. Macroscopically they found that only the rostral corpus callosum was present and the anterior commissure was enlarged. Microscopically there was severe neuronal loss with fibrillary gliosis in the infundibular areas of the hypothalamus, particularly involving the arcuate nuclei and pre-mamillary areas.

The hypothalamus has long been recognised as important in thermoregulation (Hardy, 1961). Present views argue either in favour of a dual function for the anterior hypothalamus, which controls heat dissipating and conserving mechanisms while the posterior areas act as a relay centre (Bligh, 1966), or, conversely, that the anterior hypothalamus controls heat dissipation and the posterior controls heat conservation (Hardy, 1961; Cooper, 1966). Experimental work in the cat and goat has shown that stimulation and damage placed in the anterior hypothalamus or closely related areas have resulted in hypothermia, hyperglycaemia, panting at inappropriate temperatures with a low set 'thermostat', inhibition of shivering and coma (Andersson et al., 1956; Bond et al., 1957).

Of the five studies on temperature regulation in patients with diencephalic epilepsy, two appeared to have intact heat dissipating mechanisms but a low set 'thermostat' (Duff et al., 1961; Shapiro et al., 1969), one had impaired response to warming and intravenous pyrogen (Duff et al., 1961), one responded normally to intravenous pyrogen

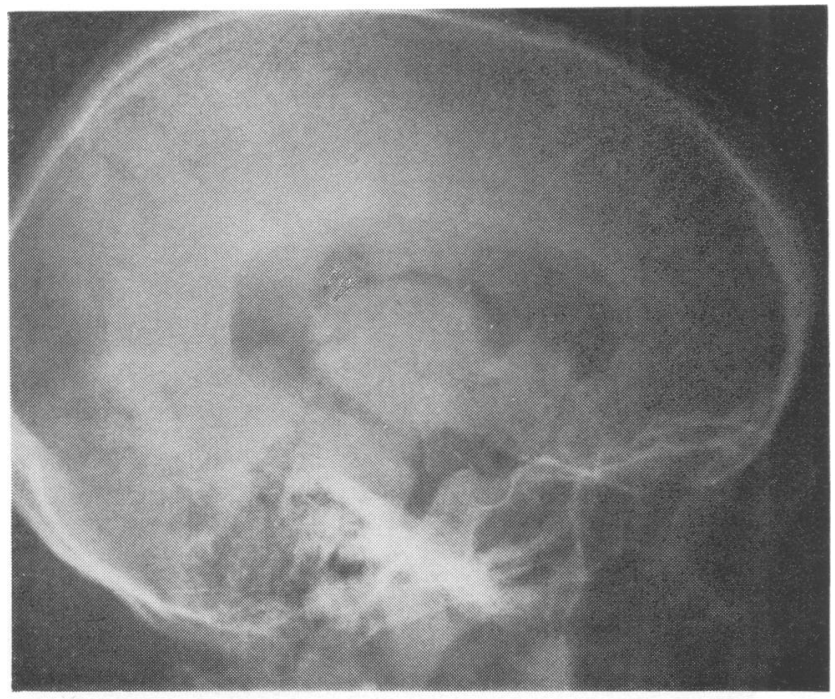

Fig. 3
Figs. 2 and 3 Anteroposterior and lateral views of pneumoencephalogram demonstrating the typical features of agenesis of the corpus callosum with wide separation of the lateral ventricles and elevation of a normal sized third ventricle. 

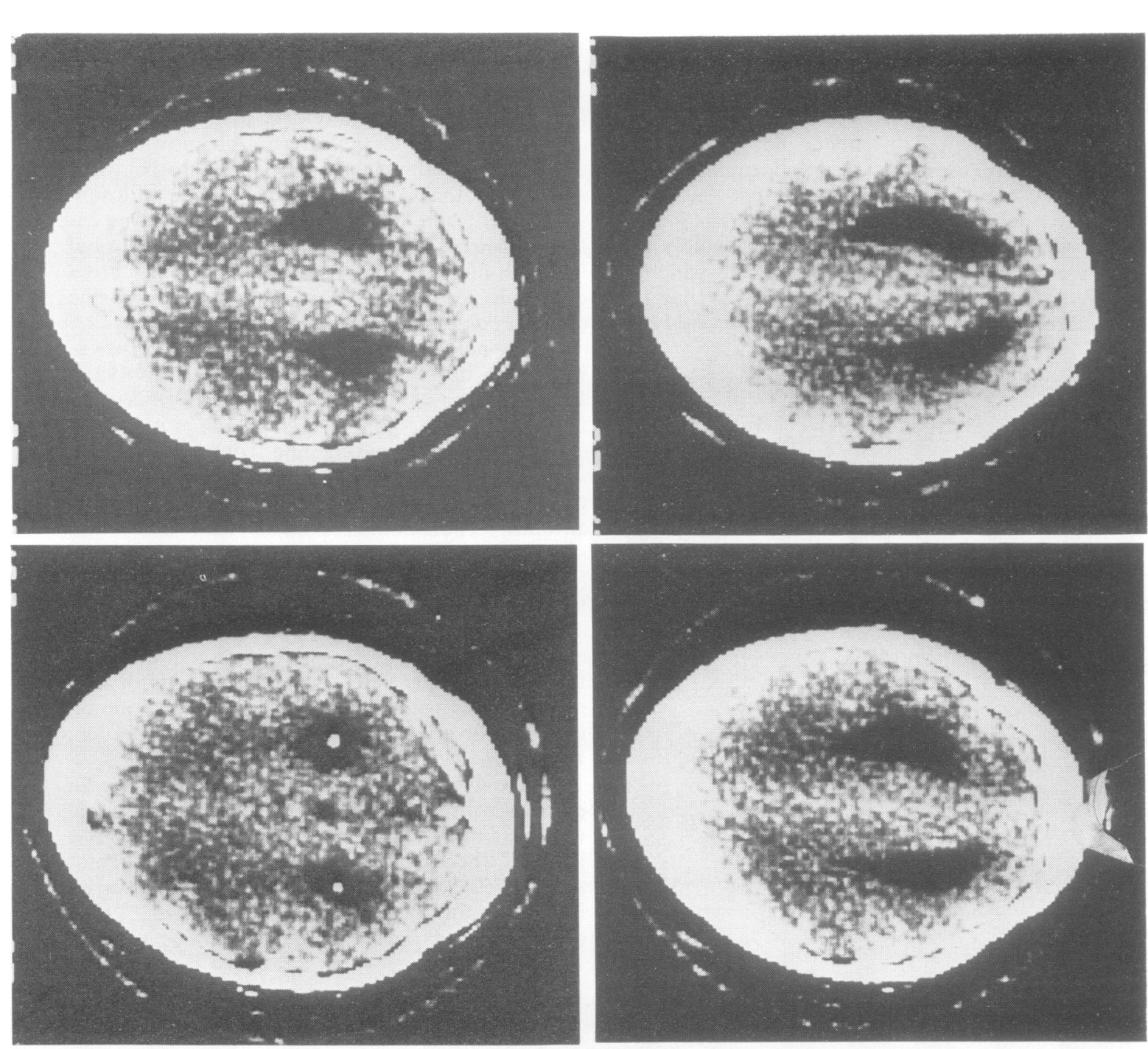

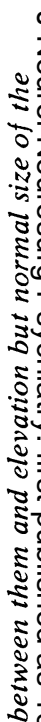
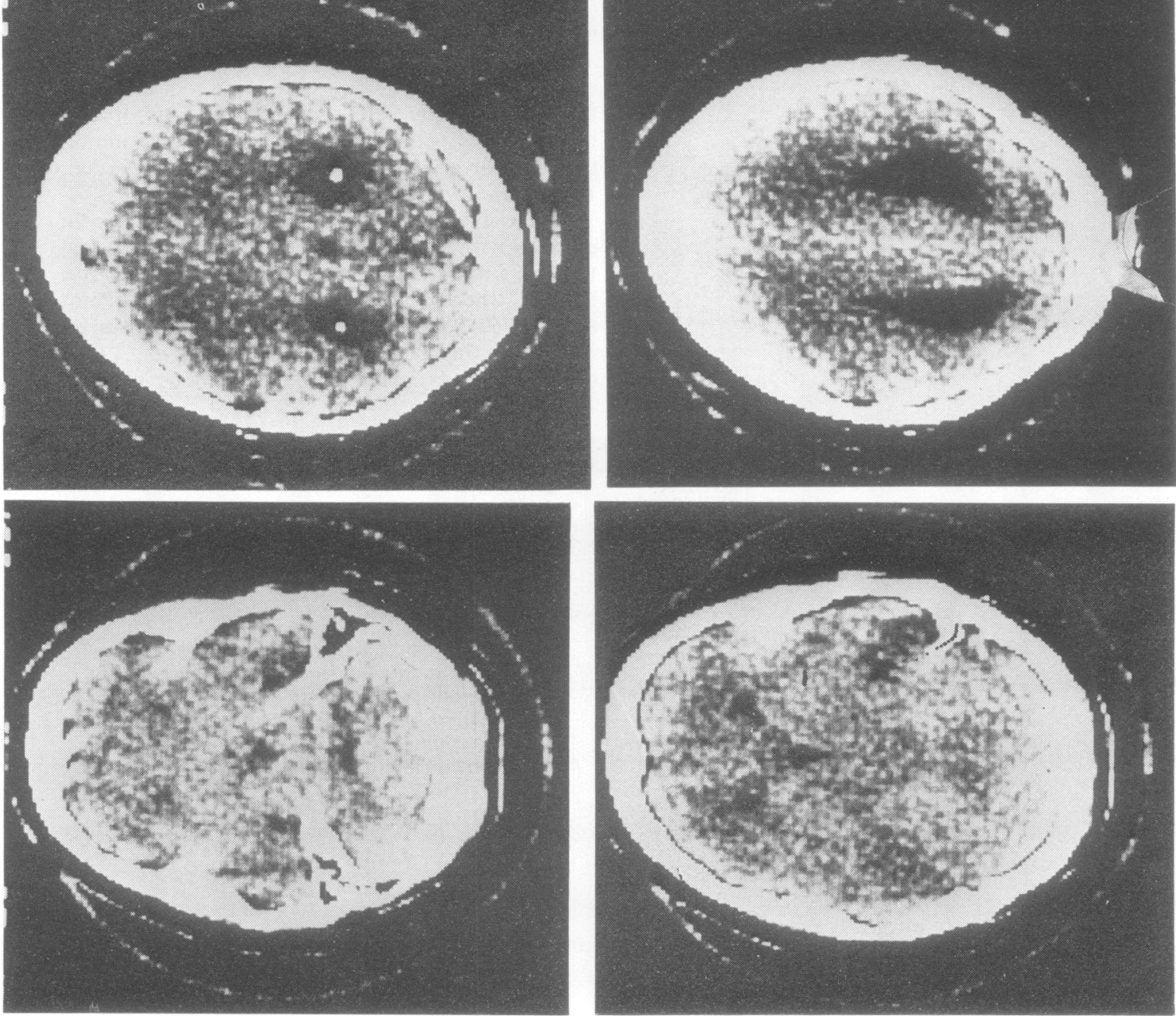
(Duff et al., 1961), one responded normally to intravenous typhoid vaccine (Shapiro et al., 1969), and one was shown to have attacks independent of skin or core temperature with no 'trigger point' (Fox et al., 1973). In this last case the orderly sequence of events during an attack was well documented as a coordinated, vasomotor, and sudomotor response with heat conserving mechanisms completely inhibited until an attack was over. Our patient similarly showed this pattern of events, and although her heat dissipating and conserving mechanisms were intact between attacks, the abnormal response described is consisient with a low setting of the physiological 'thermostat'.

The cxact mechanism of diencephalic epilepsy remains unknown. Neuronal discharge from a hypothalamiz clefect would seem an attractive suggestion to correlate many of the clinical, pathological and experimental findings. The inconstant association with agenesis of the corpus callosum, however, leaves us with the supposition of a hypothalamiz abnormality in the other cases, but in all it must be very localised and selective to account for the lack of other features of hypothalamic dysfunction. Only onc case had testicular atrophy (Noël et al.. 1973) and one amenorrhoea (Shapiro et al., 1969).

The increased availability of the EMI scanner should allow investigation of selected patients who would otherwise have been subjected to pneumoencephalography. It has shown its value in our patient not only by demonstrating the recognised features of agenesis of the corpus callosum but also by excluding a cysitic or vascular midline mass when the procedure was combined with intravenous contrast medium.

Although total sympathectomy seems the only definitive way of controlling disabling symptoms at present, a more fruitful approach might be to consider the effects of agonists and antagonists of neurotransmitter amines on the hypothalamus. The roles of a cholinergic heat production system, and a noradrenergic sysiem concerned with heat dissipation have been mentioned previously (Fox et al., 1970; Noël et al., 1973). It would seem logical, thereforc, that a central inhibitor of noradrenaline may lave a beneficial effect in diencephalic erilepsy. Morc recently bromocriptine, a doraminergic receptor agonist with weak adrenergic blocking actions, has been shown to inhibit the excessive sweating associated with Parkinson's disease and acromegaly (Thorner, 1975). While this may not be strictly relevant to the mechanism underlying sweating in diencephalic epilepsy, it would seem reasonable to attempt treatment of this distressing symptom in the same way in view of the presumed central, and thus possibly hypothalamic, origin for excessive sweating in these other conditions.

The disorder may be more common than its reported incidence would indicate. The variety of diagnoses attached to many of these patients during their long histories ranges from hypopituitarism and 'atypical liver failure' to psychoneurosis, schizophrenia, and hysteria. Our patient's symptoms were considered to be 'functional' for 20 years. There is, of course, a very low index of suspicion for spontaneous hypothermia in the adult who seems to be normal between attacks. Low body temperatures are seldom measured accurately in routine clinical practice, and this fact coupled with the poor availability of low reading thermometers, it is perhaps not surprising that the diagnosis of spontaneous hypothermia remains rare.

We wish to thank Dr K. Simpson for bringing the patient to our attention, Dr C. P. Alexander for allowing us to study the patient initially in his care, Dr Whitaker and Dr Moss for radiological investigations, Dr Lewtas for EMI scan, Miss Spreadbury for psychometric assessment, and nursing staff of Ward 1, Leicester General Hospital who made Fig. 1 possible. We are also grateful to the Department of Medical Illustration for producing the visual material.

\section{References}

Andersson. B., Grant, R., and Larsson, S. (1956). Central control of heat loss mechanisms in the goat. Acta Physiologica Scandinavica, 37, 261-280.

Bannister, R. G. (1963). The Classification and Causes of Heat Illness. DM Thesis. Oxford.

Bauer, H. G. (1954). Endocrine and other clinical manifestations of hypothalamic disease: a survey of 60 cases with autopsies. Journal of Clinical Endocrinology. 14, 13-31.

Bligh, J. (1966). The thermosensitivity of the hypothalamus and thermoregulation in mammals. Biological Reviews, 41, 317-368.

Bond, D. D., Randt, D. T.. Bidder, T. G., and Rowland, B. (1957). Posterior septal, fornical and anterior thalamic lesions in the cat. Archives of Neurology and Psychiatry (Chicago), 78, 143-162.

Bossy, J. G. (1970). Morphological study of a case of complete isolated and asymptcmatic agenesis of the corpus callosum. Archives of Anatomy, Histology and Embryology, 53, 289-340.

Cooper, K. E. (1966). Temperature regulation and the hypothalamus. British Medical Bulletin, 22, 238242. 
Cunliffe, W. J., Johnson, C. E., and Burton, J. L. (1971). Generalised hyperhydrosis following epilepsy. British Journal of Dermatology, 85, 186-188.

Davison, C., and Selby, N. E. (1935). Hypothermia in cases of hypothalamic lesions. Archives of Neurology and Psychiatry (Chicago), 33, 570-591.

Davison, C., and Demuth, E. L. (1946). Disturbances in sleep mechanisms: clinicopathological study. III. Lesions at the diencephalic level (hypothalamus). Archives of Neurology and Psychiatry (Chicago), 55, 111-125.

Duff, R. S., Farrant, P. C., Leveaux, V. M., and Wray, S. M. (1961). Spontaneous periodic hypcthermia. Quarterly Journal of Medicine, 30, 329338.

Dutau, G., Carrière, J. P., and Rochiccioli, P. (1975). Shapiro's syndrome-a recurrent spontaneous hypothermia with hypoplasia of the corpus callosum. Pédiatrie, 30, 117.

Fox, R. H., Davies, T. W., Marsh, F. P., and Urich, H. (1970). Hypothermia in a young man with an anterior hypothalamic lesion. Lancet, 2, 185-188.

Fox, R. H., Wilkins, D. C., Bell, J. A., Bradley, R. D., Browse, N. L., Cranston, W. I., Foley, T. H., Gilby, E. D., Hebden, A., Jenkins, B. S., and Rawlins, M. D. (1973). Spontaneous periodic hypothermia: diencephalic epilepsy. British Medical Journal, 2, 693-695.

Geschwind, N. (1965). Disconnexion syndrome in animals and man. Brain, 88, 237-274.

Gowers, W. R. (1907). The Borderland of Epilepsy. Blackiston's Son and Co.: Philadelphia, Pa.

Guihard, J., Velot Lerou, A., Poiteat, C., Laloum, D., and L'Hirondel, J. (1971). Hypothermie spontanée récidivante avec agénesie du corps calleux. Annales de Pédiatrie, 18, 645-656.

Hardy, J. D. (1961). The physiology of temperature regulation. Physiological Reviews, 41, 521-606.

Hines, E. A. Jr., and Bannick, E. G. (1934). Intermittent hypothermia with disabling hyperhidrosis. Proceedings of the Mayo Clinic, 9, 705-708.

Hockaday, E. D., Cranston, W. I., Cooper, K. E. and Mottram, R. F. (1962). Temperature regulation in chronic hypothermia. Lancet, 2, 428-432.

Hoffman, A. M., and Pobirs, F. W. (1942). Intermittent hypothermia with disabling hyperhydrosis. Journal of the American Medical Association., 120, 445-447.

Kaplan, H. A., Hart, J. C., and Browder, J. (1952).
Hypothermia associated with mesencephalic lesion. Journal of Neuropathology and Experimental Neurology, 11, 116-136.

Leader (1973). Lancet, 2, 246-247.

McLean, A. J. (1934). Autonomic epilepsy: report of a case with observations at necropsy. Archives of Neurology and Psychiatry (Chicago), 32, 189.

Noël, P., Hubert, J. P., Ectors, M., Franken, L., and Flament-Durand, J. (1973). Agenesis of the corpus callosum associated with relapsing hypothermia. Brain, 96, 359-368.

Obregia, A., Dimolescu, A., and Constantinescu, S. (1932). Syndrome infundibulotubérien avec troubles mentaux complexes par tumeur, supra-sellaire, du troisieme ventricule: étude anatomo-clinique. Encéphale, 27, 93-106.

Penfield, W. (1929). Diencephalic autonomic epilepsy. Archives of Neurology and Psychiatry (Chicago), 22, 358-374.

Ratner, J. (1925). Tumor des Mittelhirnes unter dem Bilde einer Pluriglandulären Insuffizienz. Klinische Wochenschrift (Berlin), iv, 599.

Shapiro, W. R., Williams, G. H., and Plum, F. (1969). Spontaneous recurrent hypothermia accompanying agencies of the corpus callosum. Brain, 92, 423436.

Siniavskaia, O. A. (1970). Hypothalamic (diencephalic) epilepsy in a seven year old girl (in Russian). Pediatriia, 49, 78-79.

Solomon, G. E. (1973). Diencephalic autonomic epilepsy caused by a neoplasm. Journal of Paediatrics, 83, 277-280.

Sperry, R. W. (1961). Cerebral organization and behavior. Science (New York), 133, 1749-1757.

Sunderman, F. W., and Haymaker, W. (1947). Hypothermia and elevated serum magnesium in a patient with facial hemangioma extending into the hypothalamus. American Journal of Medical Sciences, 213, 562-571.

Thomas, D. J., and Green, I. D. (1973a). Periodic hypothermia. British Medical Journal, 2, 696-697.

Thomas, D. J., and Green, I. D. (1973b). Episodic hypothermia. Lancet, 2, 449.

Thorner, M. O. (1975). Dopamine is an important neurotransmitter in the autonomic nervous system. Lancet, 1, 662-664.

Wechsler, I. S. (1956). Hypothalamic syndromes. British Medical Journal, 2, 373-378. 